\title{
Comparative Ultrasonographic, Anatomotopographic and Macromorphometric Study of the Spleen and Pancreas in Rabbit (Oryctolagus cuniculus)
}

\author{
Rosen Stefanov DIMITROV \\ Trakia University, Faculty of Veterinary Medicine, Department of Veterinary Anatomy, Histology \\ and Embryology,6000 Stara Zagora, Bulgaria; rosiros38@abv.bg
}

\begin{abstract}
The study aims to perform comparative analysis of the metric anatomy of the spleen and pancreas in rabbit, determined by applying of transabdominal ultrasonography and convectional anatomical research. Twelve mature, clinically healthy New Zealand White rabbits 8 months of age from and weighed between $2.8 \mathrm{~kg}$ and $3.2 \mathrm{~kg}$ were looked at. The transabdominal B-mode ultrasonography was performed by Diagnostic Ultrasound System. The spleen and pancreas were imaged sagittally and transversally. The approaches were percutaneous transabdominal hypochondral left and percutaneous transabdominal epigastric. After euthanizing the animals a laparotomy was performed. The topography, shape and morphometry were made. In longitudinal ultrasongraphic study of the spleen has been seen its elongated shape. There were ultrasonographic metric data presented. The organ was seized to the greater curvature of the stomach in the area of the bottom and portions of the body of the stomach. The ultrasonography and postmortem study showed that the pancreas in rabbit is disseminated organ. The body of the pancreas was localized in the mesoduodenum of the duodenal sigmoid flexure, immediately behind the porta hepatic, as it has been cut through by the portal vein. From the comparative analysis of the obtained results could be conclude, that the study of some quantitative parameters of the structure of the pancreas in rabbit should contribute to the accurate diagnostics of the pancreatic lesions and the abdominal surgical practice in the animals.
\end{abstract}

Keywords: measurement, rabbit, sonoanatomy, viscera

\section{Introduction}

The rabbit is a good experimental clinico-anatomical model in the research of number of morphological anomalies and diseases in humans and animals (Abidu-Figueiredo et al., 2008). Due to that, some aspects of microscopical anatomical structure of list of organs in rabbits are in need of more detailed description.

Detailed description of the structure of the spleen is done. The spleen is presented as an organ with dark red to dark blue color, which is localized in the left cranial part of the abdomen. It is elongated with triangular shape in transverse aspect and is located in near proximity to the greater curvature of the stomach. The size of the spleen is variable, due to their dependence of the physiological and age status of the individual (Barone, 1997; Cesta, 2006; Hristov et al., 2006).

A morphological study of the spleen is conducted in the Brazilian Armadillo. The live mass of the Brazilian Armadillo is compared to the mass of the spleen and judge for the changes in the weight when adapting to abnormal conditions Galíndez et al. (2006).

Some anatomical specifications of the pancreas in rabbit show that the gland is structured from separate and irregular parts, which are placed in the peritoneal folds. The pancreas is localized between the transverse colon, stomach, duodenum and caudal vena cava (Barone, 1997; Brewer, 2006).

Macroanatomical study of the pancreas in the wild dog demonstrate that the pancreas is placed from the hilus of the spleen (to the left) to the beginning of the transverse portion of the duodenum (to the right) (Grace $e t$ al., 1988).

The pancreas in the Reindeer is similar to that of the small dairy animals. The gland was a slightly yellow, lobulated and soft. The pancreas consists of two lobes (left and right). The left lobe (tail) extending in a dorsoventral direction and it is in contact with rumen, spleen, and the left adrenal gland. The right lobe (head) lies within the curve of the duodenum. The major pancreatic duct opens into common bile duct (Nikander, 1990).

The pancreas in rats consists of a biliary (body), duodenal (right part) and gastrosplenic portions (left part). The pancreatic body was located along the cranial part of duodenum. The right lobe extended into the duodenal ligament. The left lobe extended toward the spleen into the gastrolienal ligament. The anatomic features in the rat may guide investigations in experimental surgical studies (Kara, 2005; Miyaki et al., 1994).

Slack (1995) showed in the anatomical study of pancreas in human that the pancreas is connected to the duodenum by the ampulla of Vater, where the main pancreatic 
duct joins with the common bile duct. In the human, the terms head, neck, body and tail are used to designate regions, while in rodents the shape of the pancreas is rather less well defined (Slack, 1995). The structure of the human pancreas retains developed anatomical traits in comparative anatomy, understanding of which contributes to the pancreatic surgical practice (Hagai, 2003; Kimura, 2003).

For the length and the weight of the human pancreas, there were no significant differences between male and female (Firoz, 2010).

The rabbit spleen was studied sonographically with 10 $\mathrm{MHz}$ sectional transducer in studying of the spleen. During the ultrasound scan, the non sedated animals were put in supine position. For the spleen following aspects were investigated: the most favorable position for scanning and normal sonographic findings (shape, surface, demarcation and echogenicity) (Nastarowitz-Bien, 2010).

Sonographic morphometric studies of the spleen in humans are performed and the obtained results are interpreted depending upon the age and the sex of the individual (Konuş et al., 1998; Soyupak et al., 2002). Longitudinal dimensions of the spleen showed best correlation with age, body weight, height and surface area. The authors determined the normal range of spleen dimensions.

B-mode ultrasonography of pancreas enables evaluation of organ quantitative characteristics (Erchinger $e t a l$., 2011; Şirli and Sporea, 2010).

The study of the gland includes transverse, longitudinal and oblique scans. The results of the size of the pancreas are in correlation to the weight, height, surface of the body and the age of the individual (Dancyngier, 1988; Ueda, 1989).

The measured metric parameters of the human pancreas decrease with age (Martínez-Noguera and D'Ontorio, 2007).

The quantitative ultrasonographic characteristics of the pancreas in healthy dogs and cats are studied (Etue $e t$ al., 2001; Heicht et al., 2006; Heicht and Henry, 2007; Larson et al., 2005). There were comparative data obtained for the three lobes of the gland and for the width of the pancreatic duct, depending on the age and physiological status. By the known so far, the present study is needed for the precise measure of the quantitative parameters of the studied organs in the domesticated rabbit.

The aim of these particular experiments is to perform comparative analysis of the metric anatomical meaning of the spleen and pancreas in rabbit, determined by the use of the transabdominal ultrasonography and convectional anatomical research.

\section{Materials and methods}

\section{The object of the study}

Twelve mature, clinically healthy New Zealand White rabbits, 8 months of age and weighed between $2.8 \mathrm{~kg}$ and $3.2 \mathrm{~kg}$ were investigated.
Quantitaive ultrasonographic study

The B-mode ultrasonography was performed by Diagnostic Ultrasound System: model DC-6V Shenzhen Mindray Bio-medical, Electronics Co. Ltd (CHINA) and microconvex, multifrequency transducer model 6C2 with working frequency $6.5 \mathrm{MHz}$ and radius $20 \mathrm{~mm}$. The abdominal wall hair was shaved between the area of the costal arch, xyphoid and the navel by means of Animal clipper device-Moser Animalline: ARCO, Type 1854, Production: Wahl Gmbh (Germany). Contact gel was used (Ecoultragel Pirrone \& Cö., Italy). The findings were documented with Mitsubishi P 91E termoprinter device. The animals were anesthtized with $15 \mathrm{mg} / \mathrm{kg}$ Zoletil 50 (tiletamine hydrochloride $125 \mathrm{mg}$ and zolazepam hydrochloride $125 \mathrm{mg}$ in $5 \mathrm{ml}$ of the solution) Virbac, France. The rabbits were positioned in supine recumbency. The spleen was imaged longitudinally and transversally. The approach was percutaneous transabdominal hypochondral left. The pancreas was scanned ultrasonographically longitudinal and transverse. Ultrasonographic access was percutaneous transabdominal epigastric and transgastric (Erchinger et al., 2011; Şirli and Sporea, 2010). The statistical analysis (descriptive statistics) of ultrasonographic measurements was performed with statistical software StatMost for Windows, version 2.50 (1995).

\section{Anatomotopographic study}

The animals were euthanized with $150 \mathrm{mg}$ i. v. Thiopental (thiopental sodium $1000 \mathrm{mg}$ ) Biochemie, Austria (10). Right after that the animals was performed laparotomy. The topography and shape of the spleen and pancreas were studied. The results were documented with digital camera Canon Legria HF R16E (Canon Inc. Japan).

\section{Macromorphometric study}

Macroscopic linear measurements of the spleen and pancreas in rabbit were studied after extirpiration of the organs. For that purpose Standard Caliper - MITUTOYO D-2 (USA) was used. The statistical analyses (descriptive statistics) were performed with statistical software StatMost for Windows, version 2.50 (1995).

\section{Ethical protocol}

The study was approved by the institutional committee of animal care. The experiments were made in strict compliance with European convention for vertebrate animals' protection, used for experimental and other scientific purposes (Starsbourg $/ 16^{\text {th }}$ May, 1986), European convention for companion animals' protection (Starsbourg $/ 13^{\text {th }}$ November, 1987) and animal protection's law in Republic of Bulgaria (section IV-Experiments with animals, art. 26, 27 and 28 , received on $24^{\text {th }}$ January 2008 and published in Government Gazette, № 13, 2008). 
16

\section{Results and discussion}

The longitudinal ultrasonographic scope of the spleen had helped visualizing its elongated shape (Fig. 1). The length varied from $32.7 \mathrm{~mm}$ to $33.3 \mathrm{~mm}$ and it had been with average value of $33 \pm 0.05 \mathrm{~mm}$ and standard deviation $0.18 \mathrm{~mm}$. The dorsal end of the spleen showed the greatest width, which had average value of $13 \pm 0.05 \mathrm{~mm}$, varied from $12.7 \mathrm{~mm}$ to $13.3 \mathrm{~mm}$ and standard deviation 0.17 $\mathrm{mm}$. The ventral end showed the smallest width, varied from $6 \mathrm{~mm}$ to $6.6 \mathrm{~mm}$, average of $6.3 \pm 0.06 \mathrm{~mm}$ and standard deviation of $0.22 \mathrm{~mm}$. To the middle part the spleen was narrower, as showed average width of $8.1 \pm 0.07 \mathrm{~mm}$ (Tab. 1). In transversal ultrasonographical representation the shape of the organ was oval to triangular (Fig. 2). The mediolateral size (width) was $6.3 \pm 0.05 \mathrm{~mm}$, varying from $6 \mathrm{~mm}$ to $6.6 \mathrm{~mm}$ and showed standard deviation of 0.18 $\mathrm{mm}$. Dorsoventral size was with average of $3.4 \pm 0.06 \mathrm{~mm}$,

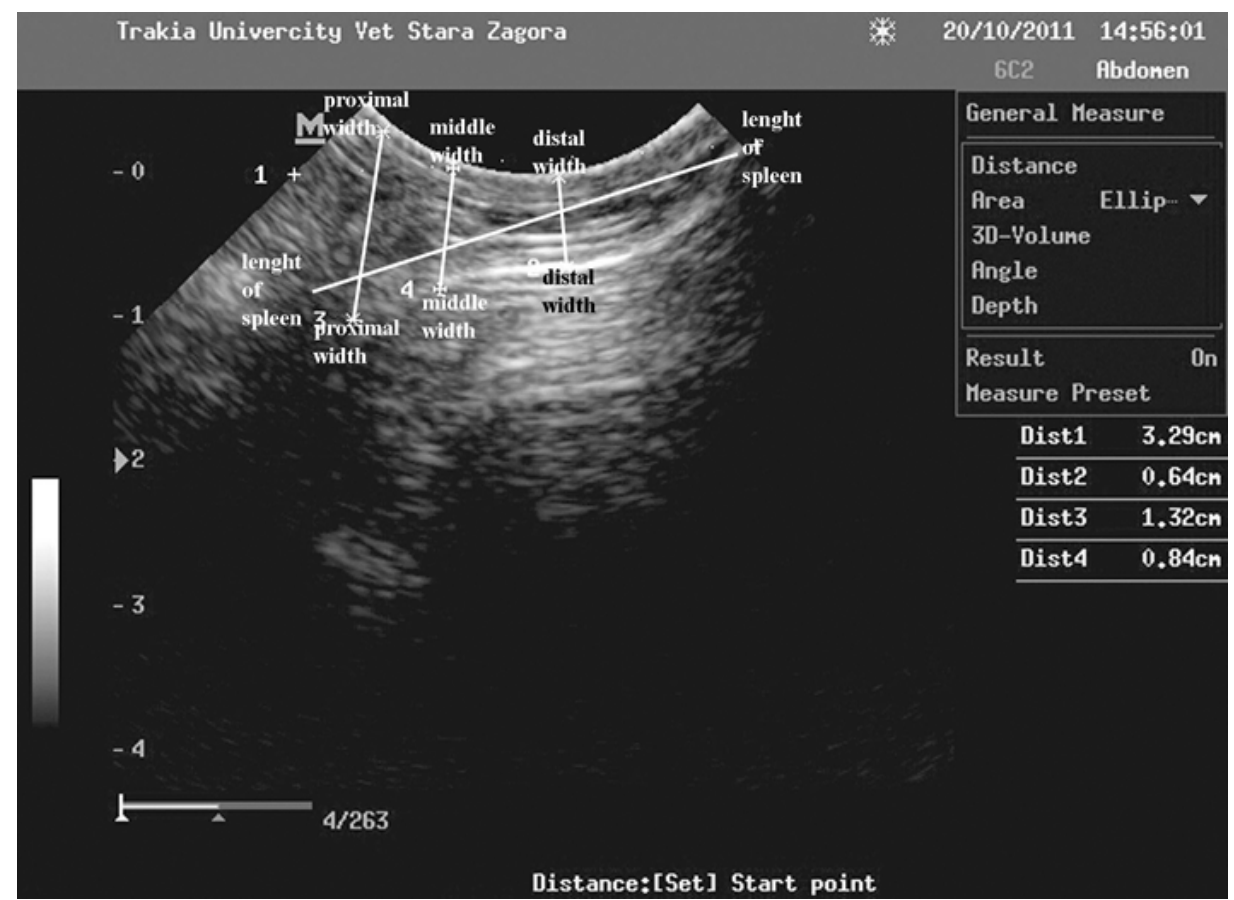

Fig. 1. Measurements of two-dimensional longitudinal ultrasonographic image of rabbit spleen

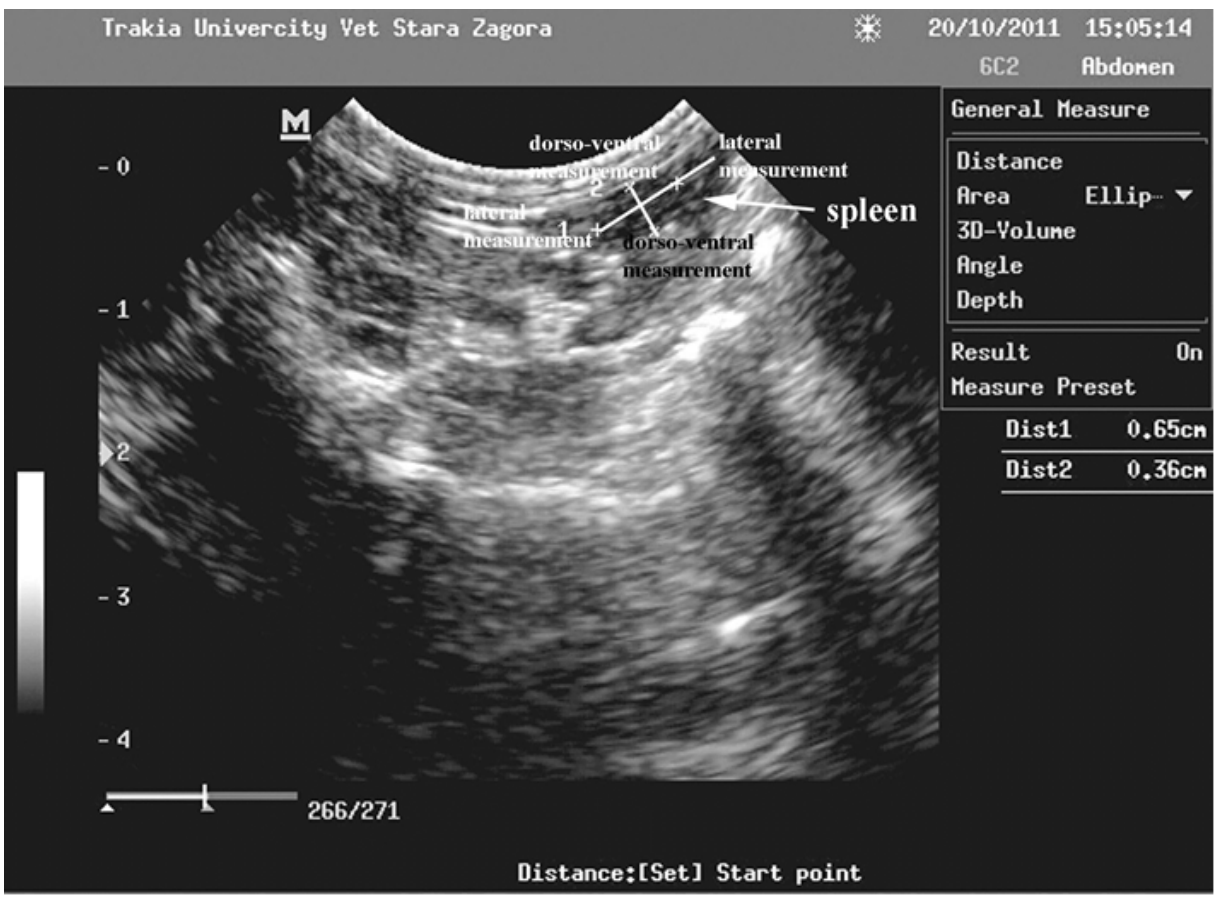

Fig. 2. Measurements of two-dimensional transversal ultrasonographic image of rabbit spleen 
Tab. 1. Measured ultrasonographic parameters (in $\mathrm{mm}$ ) of the normal spleen and pancreas of white New Zealand rabbit

\begin{tabular}{|c|c|c|c|c|c|c|c|c|}
\hline $\begin{array}{l}\text { Ultrasono- } \\
\text { graphic image }\end{array}$ & $\mathrm{N}$ & Parameters & Range & Minimum & Maximum & Mean & $\begin{array}{c}\text { Standart } \\
\text { Error }\end{array}$ & $\begin{array}{l}\text { Standart } \\
\text { Deviation }\end{array}$ \\
\hline \multirow{4}{*}{$\begin{array}{l}\text { Longitudi-nal } \\
\text { image of spleen }\end{array}$} & 12 & Length of spleen & 0.6 & 32.7 & 33.3 & 33 & 0.05 & 0.18 \\
\hline & 12 & Dorsal width of spleen & 0.6 & 12.7 & 13.3 & 13 & 0.05 & 0.17 \\
\hline & 12 & Middle width of spleen & 0.6 & 7.9 & 8.5 & 8.1 & 0.07 & 0.22 \\
\hline & 12 & Ventral width of spleen & 0.6 & 6 & 6.6 & 6.3 & 0.06 & 0.21 \\
\hline \multirow{2}{*}{$\begin{array}{l}\text { Transver-sal } \\
\text { image of spleen }\end{array}$} & 12 & Mediolateral measurements of spleen & 0.6 & 6 & 6.6 & 6.3 & 0.05 & 0.18 \\
\hline & 12 & Dorsoventral measurements of spleen & 0.6 & 3.1 & 3.7 & 3.4 & 0.06 & 0.21 \\
\hline $\begin{array}{l}\text { Longitudi-nal } \\
\text { image of pancreas }\end{array}$ & 12 & $\begin{array}{c}\text { Craniocaudal measurements } \\
\text { of pancreas }\end{array}$ & 0.7 & 4.8 & 5.5 & 5.1 & 0.06 & 0.19 \\
\hline \multirow{2}{*}{$\begin{array}{l}\text { Transver-sal } \\
\text { image of pancreas }\end{array}$} & 12 & $\begin{array}{l}\text { Dorsoventral measurements } \\
\text { of pancreas }\end{array}$ & 0.3 & 3.6 & 3.9 & 3.7 & 0.03 & 0.11 \\
\hline & 12 & $\begin{array}{c}\text { Mediolateral measurements } \\
\text { of pancreas }\end{array}$ & 0.4 & 5.9 & 6.3 & 6.1 & 0.04 & 0.13 \\
\hline \multirow{5}{*}{$\begin{array}{l}\text { Dimensions of } \\
\text { extirpated spleen }\end{array}$} & 12 & Length of spleen & 4 & 54 & 58 & 56.2 & 0.73 & 1.1 \\
\hline & 12 & Dorsal width of spleen & 2 & 10 & 12 & 11.1 & 0.25 & 0.4 \\
\hline & 12 & Middle width of spleen & 2 & 9 & 11 & 9.8 & 0.12 & 0.3 \\
\hline & 12 & Ventral Middle width of spleen & 1 & 8 & 9 & 8,3 & 0.1 & 0.3 \\
\hline & 12 & Thickness of spleen & 1 & 5 & 6 & 5.6 & 0.09 & 0.27 \\
\hline
\end{tabular}

minimal and maximal value of $3.1 \mathrm{~mm}$ and $3.7 \mathrm{~mm}$ and standard deviation $0.21 \mathrm{~mm}$ (Tab. 1).

Anatomotopographic study showed that the spleen was attached to the greater curvature of the stomach in the area of the bottom and portions of the body of the stomach. The dorsal and medial thirds were localized to the left intrathoracically. The ventral end prominated under the costal arch and curved medially. The spleen touched the left abdominal wall and the left liver lobe (Fig. 3). In the study done on the extirpated organ was determined that the length of the spleen varied from $54 \mathrm{~mm}$ to $58 \mathrm{~mm}$, average $56.2 \pm 0.73 \mathrm{~mm}$ and standard deviation $1.1 \mathrm{~mm}$. The width of the spleen was $11.1 \pm 0.25 \mathrm{~mm}$, as it varied from $10 \mathrm{~mm}$ to $12 \mathrm{~mm}$ and standard deviation $0.4 \mathrm{~mm}$. The ventral end of the organ showed width of $8.3 \pm 0.1$ $\mathrm{mm}$, varied from $8 \mathrm{~mm}$ to $9 \mathrm{~mm}$ and standard deviation $0.3 \mathrm{~mm}$. The middle part was with intermediate values comparing to the previous parts (Tab. 1). The shape of the spleen in the rabbit was elongated, oval, sharper toward both ends and narrower in ventral direction. The color of the investigated organ was dark red (Fig. 4).

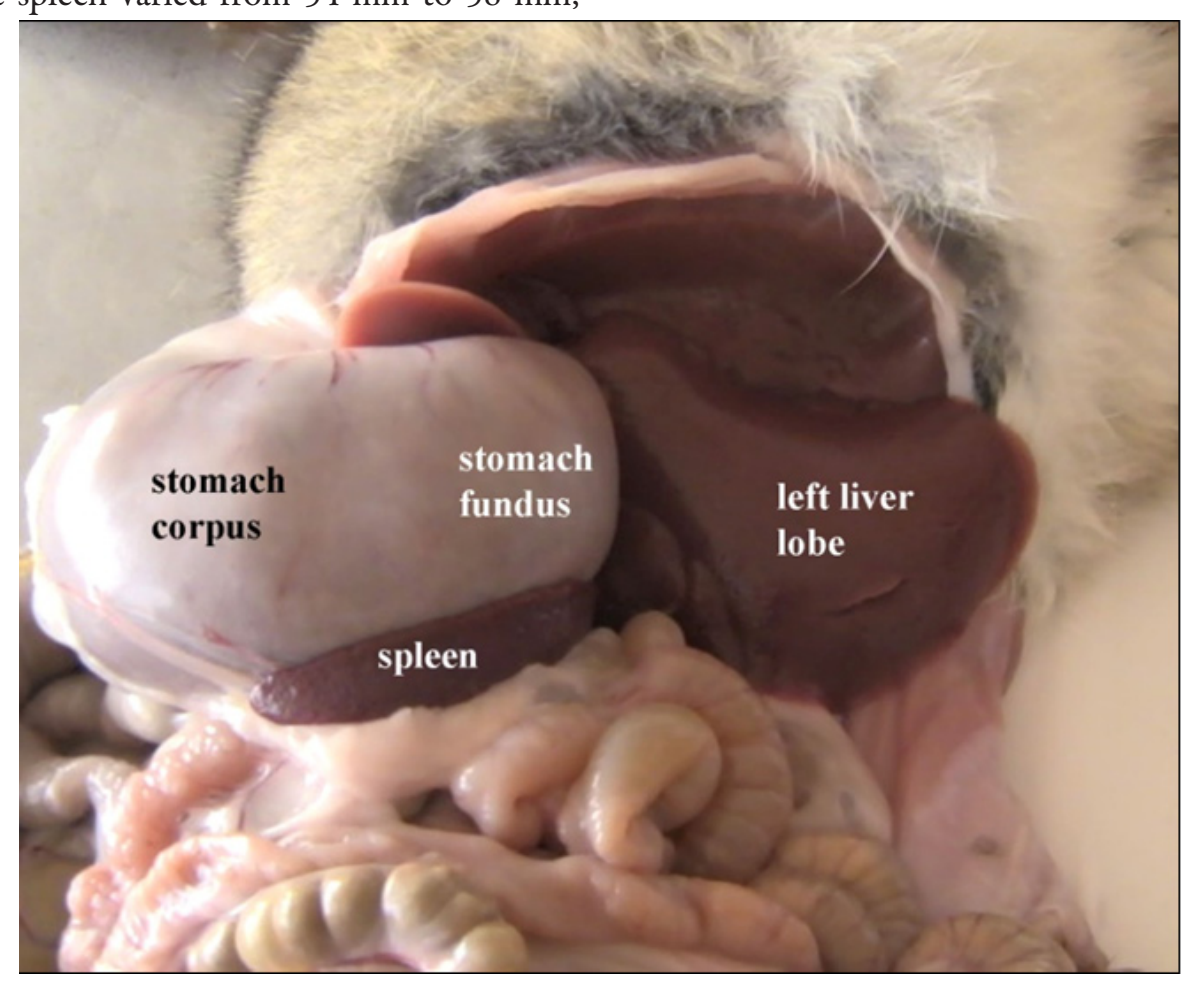

Fig. 3. Anatomotopographical localization of the spleen in rabbit 
18

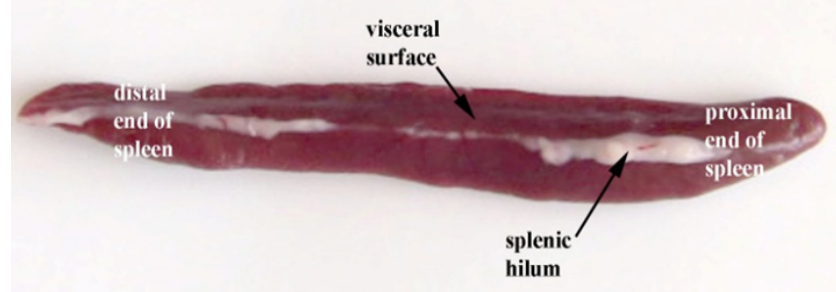

Fig. 4. Shape of the spleen in the rabbit
The ultrasonogrhaphic study showed that the pancreas in the rabbit is disseminated organ, which middle portion (body) was most compact and therefore the major measurements were performed on it. In longitudinal sonographic image of the gland was determined that the craniocaudal diameter of the pancreas had median values of $5.1 \pm 0.06 \mathrm{~mm}$, with minimal and maximal parameters respectively $4.8 \mathrm{~mm}$ and $5.5 \mathrm{~mm}$ and standard deviation $0.19 \mathrm{~mm}$ (Fig. 5, Tab. 1). In transverse sonographic image of the gland the dorsoventral diameter was $3.7 \pm 0.03$ $\mathrm{mm}$ and variability from $3.6 \mathrm{~mm}$ to $3.9 \mathrm{~mm}$ and showed

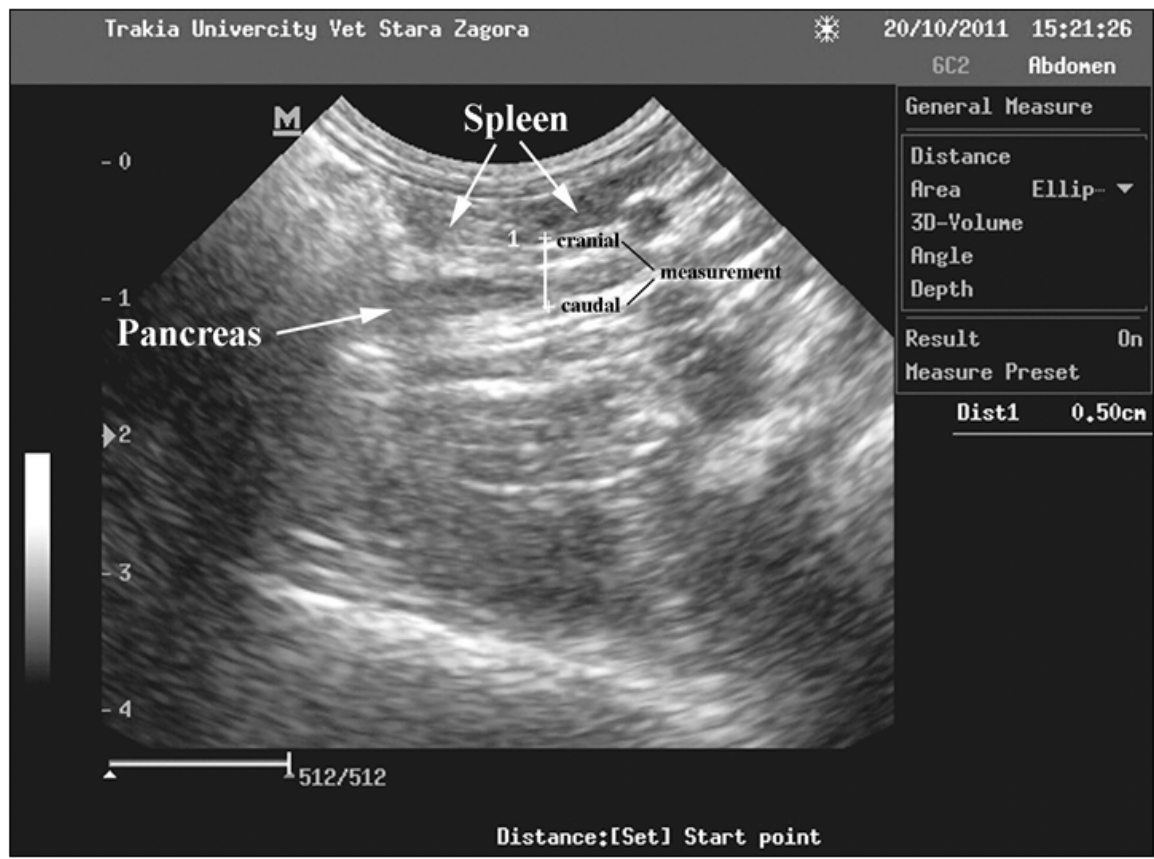

Fig. 5. Measurements of two-dimensional sagital ultrasonographic image of body of rabbit pancreas

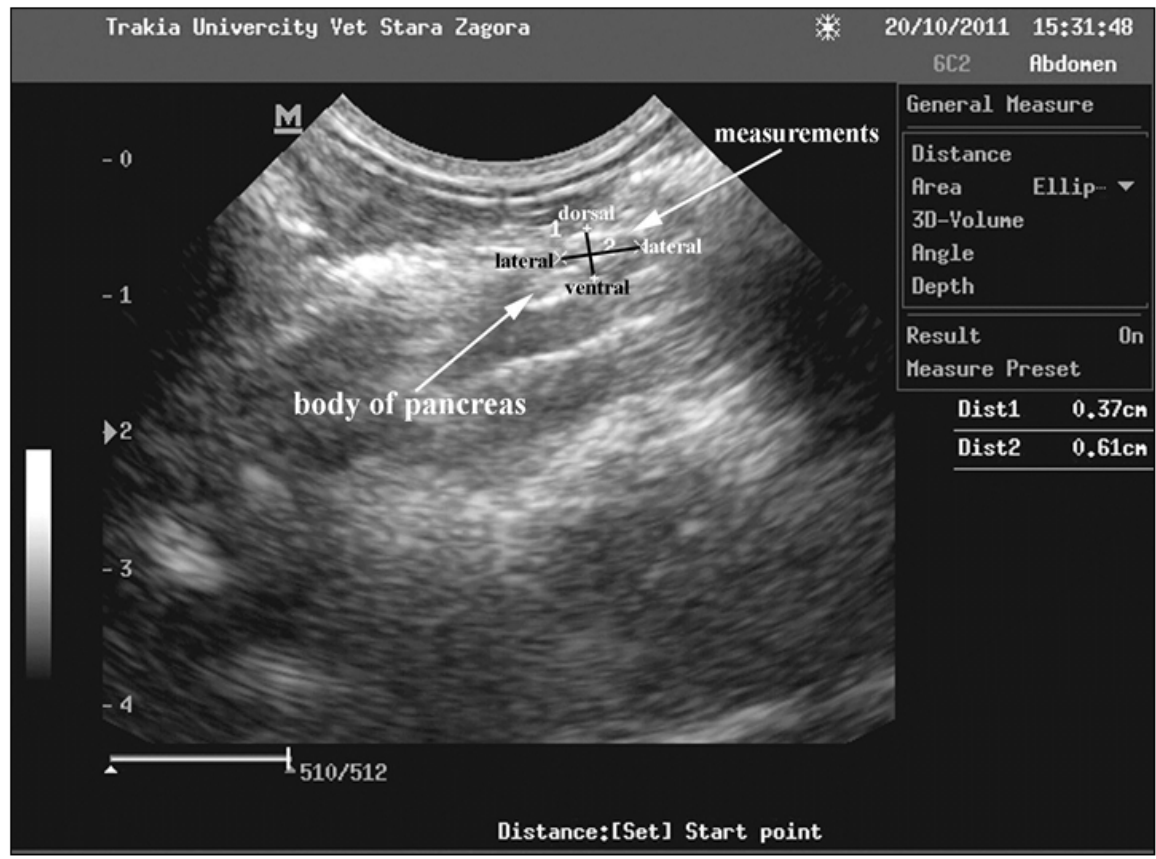

Fig. 6. Measurements of two-dimensional transversal ultrasonographic image of body of rabbit pancreas 


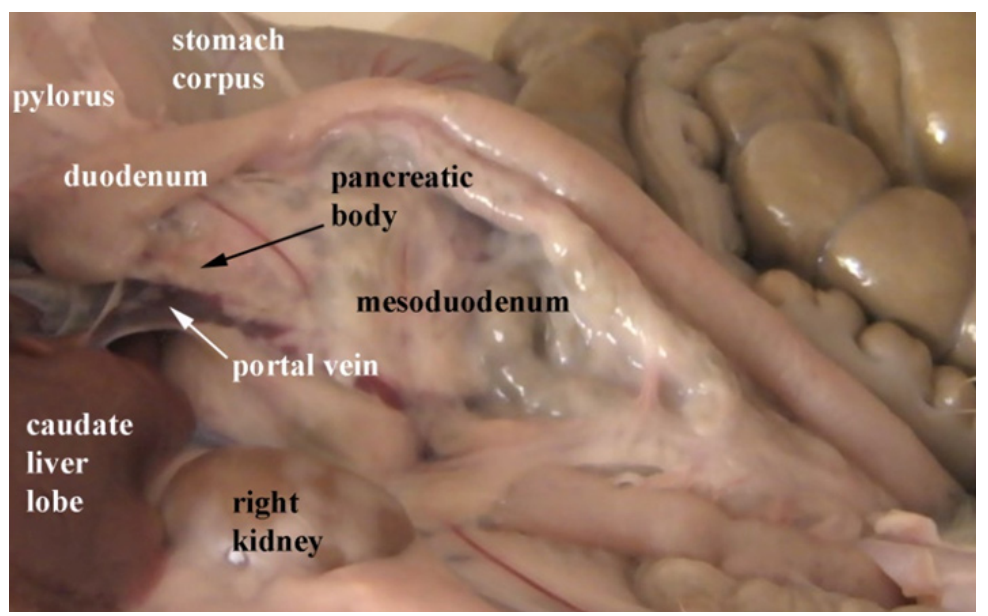

Fig. 7. Anatomotopographical localization of the pancreas in rabbit

standard deviation of $0.11 \mathrm{~mm}$. The mediolateral measurement of the pancreas was with minimal and maximal value of $5.9 \mathrm{~mm}$ to $6.3 \mathrm{~mm}$, as median was $6.1 \pm 0.04 \mathrm{~mm}$ and standard deviation $0.13 \mathrm{~mm}$ (Fig. 6, Tab. 1). The body of the pancreas was localized in the mesoduodenum of the duodenal sigmoid flexure, immediately behind porta hepatic, as through it passed the portal vein (Fig. 7, Tab. 1).

The metric results of the ultrasonoghrapic study of the spleen proved its elongated band shape as narrowed ventrally. The mediolateral measurement of the organ is nearly two times the dorsoventral, which confirms the determined shape. The obtained lower ultrasonographical values for the length of the gland, compare to the results from postmortem morphometric measures are due to the fact that with sonogrhaphy are only visualized the topmost dorsal two thirds of the spleen. The data for the dorsal, medial and the ventral width of the extirpared spleen are much closer to the ones obtained via ultrasonography, which is a confirmation of the reliability of the sonographic results.

The determined localization, shape and color of the spleen in the rabbit correspond with the data from the study of Barone (1997), Cesta (2006) and Hristov et al. (2006) who give presentation of the gland as an organ with dark red color and localization in the left cranial part of the abdominal cavity.

Unlike Galíndez et al. (2006), who compare the body mass of the Brazilian Armadillo to the mass of the spleen, data for the compatibility of the metric and the sonographic results were presented.

Despite the study of Nastarowitz-Bien (2010), in which when imaging the spleen is used sector transducer with frequency of $10 \mathrm{MHz}$, in the present study is used one with frequency of $6.5 \mathrm{MHz}$. Like Nastarowitz-Bien (2010) a supine position of the investigated animals is applied for the visualization of the spleen.

Unlike the investigation of Konuş et al. (1998) and Soyupak et al. (2002), who interpret their results for the spleen in humans according to the age, sex and the body parameters, in the present investigation a comparative estimation of the data of sonographic and postmortem examinations is performed.
From the results of the sonographic and convectional metric survey of the spleen it could be concluded the following: sector transducer with frequency of $6.5 \mathrm{MHz}$, used for ultasonographic visualization of the spleen in the rabbit is entirely suitable for the full imaging of the organ; the positioning of the animals in dorsal recumbency is good choice for the ultrasonographic study of the spleen; the transabdominal percutaneus sonographic access is sufficiently definitive for the measurements of the quantitative parameters of the spleen.

The obtained data for the localization of the body of pancreas correspond with the information from Barone (1997) and Brewer (2006) regarding the topography and the structure of the normal pancreas in the rabbit. The place of the passage of the portal vein through the body of the gland is good vessel marker.

In comparison to the data from Grace et al. (1988), Kara (2005) and Miyaki et al. (1994) for the topography and length of the pancreas in the wild dog and the rat are presented results only for the body of pancreas. The reason being is the disseminated character of the glandular macrostructure.

Despite the Reindeer's pancreas which has yellow color and consists of two lobes (Nikander, 1990), in the rabbit the pancreas is dark red and with three lobes. Data are also presented for the the most compact lobe - the body of the pancreas.

The results demonstrate that the pancreas in the rabbit, similar to that in rodents does not have separated lobes (Slack, 1995).

Unlike the results of the Dancyngier (1988), MartínezNoguera and D'Ontorio (2007) and Ueda (1989) a correlation between rabbit's body parameters and its age isn't made

In comparison to the research from Etue et al. (2001), Heicht et al. (2006), Heicht and Henry (2007) and Larson et al. (2005), done on quantitative ultrasonograhic characteristics of the pancreas in healthy dogs and cats, the results aren't commented depending upon the physiological status of the studied animals. 
20

From the comparative analysis of the produced data, like other authors (Hagai, 2003; Kimura, 2003; Kara, 2005; Miyaki et al., 1994) the investigation of some quantitative parameters in the pancreatic structure in the rabbit could contribute for the diagnostics of pancreatic lesions and abdominal surgical practice in animals.

The obtained data confirmed the published opinions from Abidu-Figueiredo et al. (2008), that the rabbit is a good experimental model when studying list of morphological anomalies and diseases in humans and animals.

\section{Conclusions}

The ultrasonographical values for the length of the gland, compare to the results from postmortem morphometric measures are due to the fact that with sonogrhaphy are only visualized the topmost dorsal two thirds of the spleen.

The pancreas in the rabbit is disseminated organ, which middle portion (body) was most compact and therefore the major measurements were performed on it. The investigation of the normal pancreas of the rabbit could contribute for the diagnostics of pancreatic lesions in animals.

\section{References}

Abidu-Figueiredo M, Xavier-Silva B, Cardinot Th, Babinski M, Chagas M (2008). Celiac artery in New Zealand rabbit: anatomical study of its origin and arrangement for experimental research and surgical practice. Pesquisa Vet Brasil 28(5):237 240.

Barone R (1997). Chapitre VII-Pancréas, Splanchnologie I, 560-575 p. In: Anatomie comparée des mammifères domestiques. Tome troasième, Troisième edition, Ed Vigot, Paris.

Barone R (1997). Chapitre VIII-Rate, Splanchnologie I, $577-$ 591 p. In: Anatomie comparée des mammiferes domestiques. Tome troasième, Troisième edition, Ed Vigot, Paris.

Brewer N (2006). Biology of the rabbit. J Am Assoc Lab Anim 45(1):8-24.

Cesta M (2006). Normal structure, function, and histology of the spleen. Toxic Pathol 34(5):455-465.

Dancyngier H (1988). Songraphy of the pancreas.

Erchinger F, Dimcevski G, Engjom T, Gilja O (2011). Transabdominal ultrasonography of the pancreas: basic and new aspects. Imaging Med 3(4):411-422.

Etue S, Penninck D, Labato M, Pearson S, Tidwell A (2001). Ultrasonography of the normal feline pancreas and associated anatomic landmarks: a prospective study of 20 cats. Vet Radiol Ultrasoun 42(2):330-336.

Firoz A (2010). A gross morphological study of human postmortem pancreas in Bangladeshi people. Bangl J Anat $8(2): 56-58$.

Estecondo S, Casenave E (2006). The Spleen of a specialy adapted mammal: The little hairy Aarmadillo Chaetophractus vellerosus, (Xenarthra, Dasypodidae). A light and electron mi- croscopic study. Internat J Morphol 24(3):339-348.

Grace P, McShane J, Pitt H (1988). Gross anatomy of the liver, biliary tree, and pancreas in the black-tailed prairie $\operatorname{dog}(\mathrm{Cy}$ nomus ludovicianus). Lab Anim 22:326-329.

Hagai H (2003). Configurational anatomy of the pancreas: its surgical relevance from ontogenetic and comparative-anatomical viewpoints. J Hepato-Biliary-Pan 10(1):48-56.

Heicht S, Penninck D, Mahony O, King R, Rand W (2006). Relationship of pancreatic duct dilatation to age and clinical findings in cats. Vet Radiol Ultrasoun 47(3):287-294.

Heicht S, Henry G (2007). Sonographic evalution of the normal and abnormal pancreas. Clin Tech Small Animal Practice 22(3):115-121.

Hristov H, Kostov D, Vladova D (2006). Topographical anatomy of some abdominal organs in rabbits. Trakia J Sci 4(3):710.

Kara M (2005). The anatomical study on the rat pancreas and its ducts with emphasis on the surgical approach. Ann Anat 187(2):105-112.

Kimura W (2003). Anatomy of the head of the pancreas and various resection procedures for intraductal papillary-mucinous tumors of the pancreas. Nihon Geka Gakk 104(6):460470.

Konuş Ö, Özdemir A, Akkaya A, Erbaş G, Çelic H, Işik S (1998). Normal liver, spleen, and kidney dimensions in neonates, infants, and children. Am J Roentgenol 171(6):1693-1698.

Larson M, Panciera D, Ward D, Steiner J, Williams D (2005). Age-related changes in the ultrasound appearance of the normal feline pancreas. Vet Radiol Ultrasound 46(3):238242.

Martínez-Noguera A, D’Ontorio M (2007). Ultrasonography of the pancreas. 1. Conventional imaging. Abdominal Imaging 32(2):136-149.

Miyaki T, Nakamata K, Akimoto T, Kitoh J, Ito H (1994). Gross morphology of the pancreas and distribution of pancreatic ducts in the rat. Jikken Dobutsu 43(2):257-260.

Nastarowitz-Bien Ch (2010). Ultrasound examination of the abdomen in rabbits. Nutzungsbedingungen Copyryght, Berlin, Germany, PhD Diss Abstr 62-73 p.

Nikander S (1990). On the anatomy and topography of the pancreas and pancreatic duct in reindeer. Rangifer 10(1):25-29.

Şirli R, Sporea I (2010). Ultrasound examination of the normal pancreas. Med Ultrasonography 12(1):62-65.

Slack J (1995). Developmental biology of the pancreas. Development 121(6):1569-1580.

Soyupak S, Narh N, Yapicioglu H, Satar M, Aksungur E (2002). Sonographic measurements of the liver, spleen and kidney dimensions in the healthy term and patern newborns. Eu J Radiol 43(1):73-78.

StatMost for Windows 2.50 (1995). Descriptive Statistics. DataMost Corporation, USA.

Ueda D (1989). Sonographic measurement of the pancreas in children. J Clin Ultrasound 17(6):417-423. 